Macedonian Pharmaceutical Bulletin, 66 (Suppl 1) 137 - 138 (2020)

Online ISSN 1857 - 8969

UDC: 615.015 .15

DOI: 10.33320/maced.pharm.bull.2020.66.03.068

Short communication

\title{
Effect of process scale-up on granulate, tablets properties and dissolution behavior in immediate release fixed-dose combination product
}

\author{
Nadica Vanova ${ }^{1,2}$, Roza Markovski ${ }^{1}$, Elena Kazandzievska ${ }^{1}$, Lile Zdraveska ${ }^{1}$, \\ Monika Kostovska ${ }^{1}$, Packa Antovska $^{1}$, Natasa Anevska Stojanovska ${ }^{1}$, Sonja Ugarkovic ${ }^{1}$ \\ ${ }^{1}$ Alkaloid AD,Pharmaceutical Chemical and Cosmetics Company, Aleksandar Makedonski 12, \\ 1000 Skopje, Republic of North Macedonia \\ ${ }^{2}$ Institute of Pharmaceutical Technology, Faculty of Pharmacy, Ss. Cyril and Methodius University, \\ Mother Teresa 47, 1000 Skopje, Republic of North Macedonia
}

\section{Introduction}

Fixed-dose combination immediate release (IR) tablets of a Biopharmaceutical classification system (BCS class) II antihyperlipidemic and I antihypertensive drug was developed as a generic product using wet granulation technology. Obtaining similarity to the reference product (RP) in order to assure similar release profile and further similar drug pharmacokinetics is a challenge, assuming that there are many influences on the active components dissolution behavior, where one of the main challenges is the process scale-up. Process and product understanding are needed in order to define the critical process parameters (CPP) and the critical quality attributes (CQAs). Further successful process parameters scaling and adaptation from laboratory scale to production scale is needed in order to assure the desired product quality. Different scale-up approaches and rules for wet-granulation are described in the literature, among are the constant impeller tip speed (Rekhi et al., 1996), specific power input (Campbel et al., 2011; Landin et al, 1996) or flow regime characterized by the dimensionless Froude number (Lister et al., 2002).
Even relatively minor parametric changes can have influence on the dissolution behavior, where granule strength and particle size distribution (PSD) of granules can be affected. In our study the dimensionless Froude number approach was used to scale the wet-granulation mixing speed from laboratory scale trial of $1 \mathrm{~kg}$ IR fixed-dose combination product from $4 \mathrm{~L}$ high shear mixer, to production scale trial of $32 \mathrm{~kg}$ produced in $65 \mathrm{~L}$ pilot high shear mixer by two granulation sub-batches.

The aim of the present work was to compare the granulate characteristics and dissolution behavior of active ingredients from final drug product.

\section{Materials and methods}

\section{Formulation}

BCS class II drug with low water solubility and BCS class I water-soluble APIs were wet granulated with excipients of common pharmaceutical usage with hydrohypropylcellulose dissolved in water as binder.

\footnotetext{
*nvanova@alkaloid.com.mk; rmarkovska@alkaloid.com.mk
} 


\section{Production process}

High-shear wet granulation and fluidized-bed drying process were used. The chopper speed and impeller speed as CPPs of the wet granulation phase were set as $1500 \mathrm{rpm}$ and $150 \mathrm{rpm}$ respectively, for 1 minute during the binder addition and $1500 \mathrm{rpm}$ and $150 \mathrm{rpm}$ respectively, for 6 minutes during the wet-massing for laboratory trial at Diosna P 4 highshear mixer granulator. For the pilot scale $1500 \mathrm{rpm}$ and $100 \mathrm{rpm}$ for the chopper and impeller were set with 2 minutes for binder addition and 3 minutes for wet-massing in Aeromatic-Fielder PMA ${ }^{\mathrm{TM}} 65$. Fluid-bed drying was carried in Hüttlin ${ }^{\circledR}$ MicroLab drier with air consumption volume of $15 \mathrm{~m}^{3} / \mathrm{h}$ and drying temperature of $60-65{ }^{\circ} \mathrm{C}$ at laboratory scale and on Aeromatic-Fielder TSG-2 using air consumption of $200-250 \mathrm{~m}^{3} / \mathrm{h}$ and drying temperature of $70-75^{\circ} \mathrm{C}$. Tablets were produced using KORSCH XL 100 laboratory scale rotary tablet press machine and Fette 2090i production scale rotary tablet press machine. Tablets were film coated in O'Hara Labcoat ${ }^{\mathrm{TM}}$ laboratory perforated film-coating machine and Glatt ${ }^{\circledR}$ production scale film-coating machine of same working principle.

\section{Testing methods}

PSD was measured using vibratory sieve Retsch AS200 Control, and granule porosity was tested on AccuPyc $^{\mathrm{TM}}$ gas pycnometer. The produced filmcoated tablets were tested for dissolution comparability to the RP by apparatus II (paddle) method using $900 \mathrm{ml}$ and $75 \mathrm{rpm}$ in different $\mathrm{pH}$ media $(2.2 ; 4.5$ and 6.8$)$. The dissolved $\%$ of each API was measured using in-house HPLC method. Comparison between laboratory and scale-up trial was made along with the comparison to the dissolution with the RP for both APIs.

\section{Results and discussion}

Similarity between PSD of the obtained granules on laboratory scale and pilot production scale demonstrated similarity $(\mathrm{t}-\mathrm{Stat}<\mathrm{t}$-Critical) with obtained bulk densities for the granulate of 0.591 $\mathrm{g} / \mathrm{mL}$ for laboratory trial and $0.694 \mathrm{~g} / \mathrm{mL}$ for scaledup product as well as granule porosity of $64.64 \%$. The produced film coated tablets had similar physical characteristics. The tablet hardness which can be directly related to the disintegration and therefore to the dissolution profile of the product, was in range of 6.63-8.15 kP and disintegration time in range of 00:00:38-00:00:47 minutes for laboratory scale and 4.59-6.12 kP for the film coated tablet hardness and 00:00:45-00:00:59 for the disintegration time of the scaled-up product. As expected, the Froude number calculation for adaptation of wet-granulation impeller speed for the scale-up at a constant chopper speed and mixing time, leaded to comparable results for the granulate and tablets characteristics and comparative dissolution profiles for both BCS class II and I APIs compared to the RP and to laboratory scale. Similarity with the RP and between laboratory scale and scaled-up trial was demonstrated in each tested $\mathrm{pH}$ media for both APIs. Similarity $f_{2}$ statistic factor with mathematical calculation was used where relevant and no mathematical calculation was used where results $\geq 85 \%$ in $15 \mathrm{~min}$ were obtained, as following the conditions described in EMA guideline on the investigation of bioequivalence (CPMP /EWP/QWP/ 1401/ 98 Rev. 1/ Corr **).

\section{Conclusion}

CPPs of the granulation process were successfully scaled-up, where Froude number calculations for the wet-granulation impeller speed at constant chopper speed and mixing time were used and the comprehensive range of parameters were successfully adapted to pilot production.

\section{References}

Campbell, G.A., Clancy, D.J., Zhang, J.X., Gupta, M.K., Oh, C.K., 2011. Closing the gap in series scale up of high shear wet granulation process using impeller power and blade design. Powder Technol. 205, 184192.

EMA, 2010. Guideline on the investigation of bioequivalence.

Landin, M., York, P., Cliff, M.J., Rowe, R.C., Wigmore, A.J., 1996. Scale-up of a pharmaceutical granulation in fixed bowl mixer-granulators. Int. J. Pharm. 133, 127-131.

Litster, J.D., Hapgood, K.P., Michaels, J.N., Sims, A., Roberts, M., Kaminini, S.K., 2002. Scale-up of mixer granulators for effective liquid distribution. Powder Technol. 124, 272-280.

Rekhi, G.S., Caricofe, R.B., Parikh, D.M., Augsburger, L.L., 1996. A new approach to scale-up of a highshear granulation process. Pharm. Technol. 20, 58-67

Maced. Pharm. Bull. 66 (Suppl 1) 137 - 138 (2020) 